\title{
WILD WEST
}

At the Endangered Species in the Prairie Provinces Workshop in Edmonton, on 25 January 1986 Monte Hummel, the president of the World Wildlife Fund (WWF) announced the offer of the WWF to make available about $\$ 600,000$ over a 3-year period to fund a conservation program in the Prairie Provinces. General guidelines can be taken from the World Conservation Strategy with its three global objectives:

1) "Maintain essential ecological processes and life support systems."

2) "Preserve the genetic diversity upon which the functioning of life support systems depends."

3) "The sustainable utilization of species and ecosystems which support millions of rural communities as well as major industries."

The program has already received unanimous approval from about 100 people chosen from all fields in the west who were contacted for discussion of the idea. The definition, control and direction taken by this Wild West program will be entirely done by western people. The Steering Committee will consist of representatives from the governments of Manitoba, Saskatchewan and Alberta, the federal government, agriculture, universities, business and nongovernment organizations which will control and direct the entire program along the lines of the World Conservation Strategy.

This program in western Canada is being sponsored by WWF because it has been recognised that this prairie area is a priority area - it is sensitive to desertification, it has numerous areas that are recognised as of world significance and it contains a concentration of endangered species and habitats. The WWF can help us to get started over the first 3 years. From then on we must generate our own funding.

WWF and the Canadian Wildlife Service have produced a poster on Prairie Endangered Species which features a painting of a Swift Fox by Michael Dumas (about $60 \times 86 \mathrm{~cm}$ or $24 \times 34^{\prime \prime}$ with an information panel in additional $60 \times 24$ $\mathrm{cm}$ or $\left.24 \times 9.5^{\prime \prime}\right)$. This will be available to schools, and a quantity will be acquired by the SNHS. For further information write to the editor or the treasurer at Box 414, Raymore, Saskatchewan. SOA 310 .

Copies of the original Discussion Paper by Monte Hummel, a summary of the Feedback from that paper, and the address given by Monte Hummel at the Endangered Species Workshop can be made available to members on request (same address). For further information on the World Wildlife Fund write to WWF, 60 St. Clair Avenue East, Suite 201, Toronto, Ontario. M4T 1N5

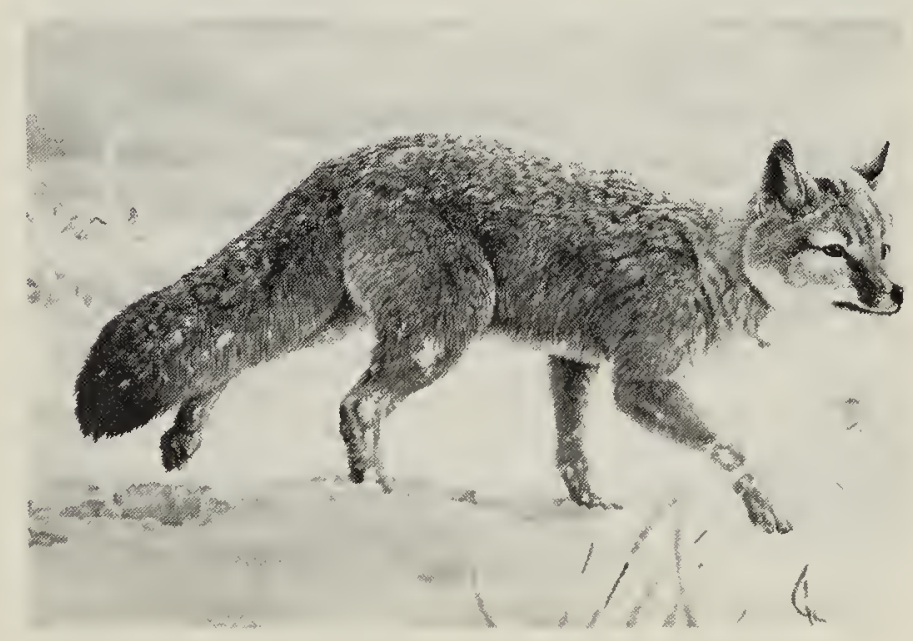

Swift Fox painting

Courtesy WWF 